\title{
The Psychological Impact of Extended Temporary Protection
}

\author{
Fethi Mansouri and Stephanie Cauchi
}

\begin{abstract}
Against the background of the recent international trend of a greater reliance on deterrence measures in managing the flow of asylum seekers, this paper discusses the implementation of the temporary protection visa (TPV) in Australia. It focuses on the psychological impact of the TPV policy on individual asylum seekers and how this unlimited temporary status affects the overall process of settlement. This study is based on personal narratives constructed by individual asylum seekers during one-onone interviews aimed at sketching the mental and psychological manifestations of stressful events in their lives as $T P V$ holders. What is particularly revealing among many of these TPV holders is the fact that their pre-migration traumatic experiences are compounded by a post-migration condition of being in indefinite "temporary" protection. This is further exacerbated by a prevalence of racialized discourses and exclusionary policies advocated by the host government. Past trauma and persecution, combined with present family separation and social exclusion, and further compounded by uncertainty about the future, had resulted in almost chronic states of anxiety and depression among a significant number of TPV holders.
\end{abstract}

\section{Résumé}

Prenant comme toile de fond la récente tendance internationale de se fier aux mesures de dissuasion pour gérer le flux de demandeurs d'asile, l'article discute de la mise en ceuvre du visa de protection temporaire (Temporary Protection Visa - TPV) en Australie. Le propos s'attarde aux répercussions psychologiques des politiques liées au TPV sur les demandeurs d'asile individuels et à la manière dont ce statut temporaire illimité touche l'ensemble $d u$ processus d'installation. L'étude se base sur des anecdotes de demandeurs d'asile relatées au cours d'interviews individuelles. Celles-ci visent à jeter un éclairage sur les manifestations mentales et psychologiques à la suite d'événements stressants qu'ils vivent en tant que détenteurs de TPV. Chez de nombreux détenteurs de TPV, il est particulièrement révélateur que les expériences traumatiques pré-migratoires sont aggravées par une condition post-migratoire de protection "temporaire» indéfinie. Cette situation se trouve exacerbée par la prédominance des discours à teneur raciste et par des politiques d'exclusion mises de l'avant par le gouvernement hôte. Les traumatismes et la persécution antérieurs, combinés à la séparation familiale et à l'exclusion sociale actuelles, sans oublier l'incertitude face à l'avenir, ont entraîné des états presque chroniques d'anxiété et de dépression parmi un nombre significatif de détenteurs de $T P V$.

\section{Introduction $^{1}$}

As Australia enters the third millennium, its multi-ethnic make up has emerged as a crucial dimension in the search for a national identity. Indeed, the 2001 Australian Bureau of Statistics (ABS) census demonstrates clearly that Australia is a genuinely multicultural society with more than 20 per cent of its people being from a non-English-speaking background (NESB). The annual intake of migrants (now in excess of one hundred thousand new arrivals each year) means that a significant number of new members of Australian society embark each year on the settlement and acculturation journey, with its many emotional and practical challenges, which affect both the individual and the host society. Unless they are carefully managed and serviced, the problems associated with settlement, cultural adjustment, loss of community standing, and separation from family and friends can lead to physical and mental health problems. Australia is one of the few countries in the world with an 
organized resettlement program for migrants, which is also extended to offshore humanitarian entrants. However, Australia has also lead the world in the implementation of policies aimed at deterring asylum seekers. These policies include mandatory detention for all onshore arrivals without documents, a three-year temporary protection visa (TPV) for those found to be refugees, and the interception of asylum seekers arriving by sea and removing them to a third country for processing. ${ }^{2}$

The focus of this paper is on the TPV which was introduced in October 1999 for asylum seekers who arrive without valid documentation and who are subsequently found to be genuine refugees. TPV holders do not have the same entitlements as permanent visa holders. ${ }^{3}$ They have limited access to Social Security, primary education, and English language classes, and are ineligible for most settlement support services. In practice, they are excluded from tertiary education, as they are not entitled to Higher Education Contribution Scheme (HECS) places and must pay full fees, and although they have the right to work their ability to do so is limited by the temporary nature of their visa, poor English language skills, and limited access to employment services. They have no automatic right of return if they leave Australia, and no right to family reunion - perhaps the most damaging restriction of the visa. Initially, it was thought that a permanent visa would be granted once the TPV expired after three years. In September 2001, however, amendments to Australia's migration legislation included the introduction of the "seven day rule." This rule prevents an asylum seeker from ever receiving a permanent visa if they have spent more than seven days in a country where they could have applied for protection. Most TPV holders who arrived after September 2001 have been affected by this. ${ }^{4}$

Over the five-year period from 2000 to 2005, most asylum seekers affected by the TPV regime were from Afghanistan and Iraq. At the end of this period the great majority $(7,803)$ of processed applicants for further protection had ultimately received a Permanent Protection Visa (PPV), with 105 receiving a further TPV. ${ }^{5}$ Of the latter cohort, 92 TPVs were granted as a result of character reasons and 13 as a result of the application of the "seven day rule." It should be noted that most of the 7,803 would have arrived before September 2001 and were therefore not subject to the "seven day rule." ${ }^{\circ}$ As at 4 November 2005, 766 applications for further protection were yet to receive a primary decision and some 1,560 persons remained on a TPV. ${ }^{7}$ Between July 2005 and February 2006 a number of TPV holders appealed the decisions made upon their applications for further protection at the Refugee Review Tribunal (RRT). This appeals tribunal recognized the need for further protection in 95 per cent of Afghan cases and 97 per cent of Iraqi cases. ${ }^{8}$ What these statistics show is that the great majority of asylum seekers subsequently affected by the TPV policy were found to be Convention refugees whose cases for permanent protection were ultimately validated by Australia's own determination mechanisms. This situation raises serious questions about the efficacy of the TPV regime. The conditions attached to TPVs deliberately create obstacles to resettlement. Yet most of those affected by the TPV will subsequently settle permanently, attracting Australia's full resettlement services. Thus the TPV policy unnecessarily prolongs and exacerbates the difficulties and costs associated with the resettlement process.

On 13 July 2004, the government announced that all TPV holders would be given the opportunity to apply for permanent visas. TPV holders, however, would not automatically qualify for permanent visas, but would simply be given the right (if eligible) to apply onshore for other non-humanitarian visas - a right denied to them since the migration legislation changes of 2001. While the thirtythree visa categories available appear to be extensive, many, such as the "Media and Film Staff," "Visiting Academic," and "Foreign Government Agency" categories, will benefit few, if any, TPV holders, while other categories, such as "Close Ties," remain unavailable. ${ }^{9}$ Some of the visas available are permanent; however others (such as student visas) are also temporary, and unlike humanitarian visas, do not engage the Australian government in any protection obligations once they have expired. Possibly of most benefit to TPV holders is the "Regional Sponsored Migration Scheme" (RSMS) visa which is available to people who have worked in regional Australia for at least twelve months. It has been amended so that employment does not need to be with one single employer and the level of functional English language required has been amended to make the category more accessible to TPV holders working in rural areas.

A "Return Pending" visa has been introduced for applicants whom the Australian government deems to be "no longer in need of protection." As at 4 November 2005, 75 such visas were in effect. ${ }^{10}$ The visa allows eighteen months for rejected applicants to make arrangements to return home and carries the same rights and restrictions as the TPV. This is undoubtedly a more humane alternative for rejected asylum seekers than (often forcible) removal or detention, which were the extant responses, and will allow them time to examine other alternatives. A "Reintegration Assistance Package" to cover travel costs and resettlement has also been offered to encourage voluntary return. However, as the majority of TPV holders are Iraqi and Afghani, the security situation in their home countries raises concerns grave enough to question the appropriateness of such an offer. 
For TPV holders wishing to remain in Australia and ineligible for alternative visas, the process of applying for a further protection visa prolongs uncertainty about the future and hinders individuals' and families' attempts to settle and build new lives. While the government's specious policy changes have neutralized critics of the TPV policy, in reality it benefits only a few existing TPV holders and, in effect, has further demoralized many of its supposed beneficiaries. As a signatory to the 1951 United Nations Refugee Convention, Australia is not obliged to provide permanent protection to refugees. However, there are compelling humanitarian and policy reasons for doing so, particularly since the majority of onshore asylum seekers in Australia since 1999 were classified as genuine refugees. ${ }^{11}$

\section{The Current Study and the Empirical Evidence}

The research findings reported in this paper are based on a larger project that was initially designed to look at the social and cultural rights of asylum seekers, and was not specifically seeking to document the mental health impacts of the TPV regime. When interviewing TPV holders, however, it became apparent that the psychological manifestations of stress and trauma were impacting upon every aspect of migrants' lives, from their ability to find and keep employment and their interest in learning English or studying, to their motivation to participate in community life and commit to a future.

Ten interviews were chosen at random from the larger pool of data that included thirty-five individual interviews and more than two hundred semi-structured questionnaires. Conducted in 2002, the interviews included in this study lasted on average forty-five minutes each and were conducted in Arabic and Farsi. We acknowledge some inherent limitations of translation and inform the reader that interviewees are identified by pseudonyms.

Content analysis was undertaken to identify major themes across all the interviews as well as in individual cases. The core themes that emerged from this analysis relate to the various phases of the asylum journey: persecution and oppression in the country of origin; uncertainty and hardship associated with the flight to a transit country of asylum; the "boat trip" en route to Australia; the detention experience; and life under the temporary protection regime. Within these broad themes the discourse analysis focused on linguistic indicators of psychological and mental status. These indicators related to explicit lexical markers of mental and psychological status, most notably: "anxiety," "uncertainty," "suffering," "fear," "pain," "torture," and "punishment." Although some of these linguistic references were more dominant than others, interviewees recorded between five and fifteen references each per interview. Table 1 provides a frequency count of linguistic references to stressful events.

- "Anxiety" appears 32 times and in all 10 interviews $(100 \%)$.

- "Fear" appears 17 times and in 9 interviews (90\%).

- "Pain" appears 7 times and in 4 interviews (40\%).

- "Uncertainty" appears 14 times in all 10 interviews (100\%).

- "Torture" appears 4 times in 2 interviews (20\%).

- "Suffering" appears 27 times in all 10 interviews (100\%).

- "Punishment" appears twice in 2 interviews (20\%).

Table 1: Quantitative summary of linguistic references to stressful events (in general)

\begin{tabular}{|l|c|c|c|c|c|c|c|c|c|c||}
\hline & Helen & Susan & Mary & Sarah & Bill & David & Larry & Colin & Peter & Jim \\
\hline \hline Anxiety & 2 & 3 & 2 & 3 & 4 & 5 & 2 & 3 & 3 & 5 \\
\hline Fear & 0 & 4 & 2 & 4 & 1 & 1 & 1 & 1 & 1 & 2 \\
\hline Pain & 0 & 1 & 1 & 2 & 0 & 0 & 0 & 0 & 3 & 0 \\
\hline Uncertainty & 1 & 1 & 1 & 1 & 2 & 2 & 1 & 1 & 1 & 3 \\
\hline Torture & 0 & 0 & 0 & 2 & 0 & 0 & 0 & 0 & 2 & 0 \\
\hline Suffering & 2 & 2 & 1 & 3 & 2 & 4 & 1 & 4 & 4 & 4 \\
\hline Punishment & 0 & 0 & 0 & 0 & 0 & 1 & 0 & 0 & 1 & 0 \\
\hline \hline $\begin{array}{l}\text { Total per } \\
\text { Interviewee }\end{array}$ & $\mathbf{5}$ & $\mathbf{1 1}$ & $\mathbf{7}$ & $\mathbf{1 5}$ & $\mathbf{9}$ & $\mathbf{1 3}$ & $\mathbf{5}$ & $\mathbf{9}$ & $\mathbf{1 5}$ & $\mathbf{1 4}$ \\
\hline
\end{tabular}


The most recurring psychological theme among interviewees was anxiety, which is mentioned by all subjects more than once during discussion. Similarly, uncertainty and suffering are mentioned by all interviewees. Suffering not only appeared most prominently among the males of the group, but it was easily the most prominent emotional response among them, with four of the six men interviewed mentioning suffering four times. Fear was also a dominant theme, mentioned by nine out of ten interviewees. This was more apparent in women - two of the four women interviewed experienced fear far more than other emotional responses - while each of the men experienced a degree of fear. Pain, torture, and punishment, reflective of the physical experiences of asylum seekers, were the least often mentioned by interviewees.

As this random sample shows, there is clearly a high level of negative feelings associated with the experiences of TPV holders. Whether talking of their past, their current situation, or their future aspirations, their psychological distress is unmistakable.

This article discusses the psychological impacts of the various stages of the asylum journey identified by interviewees. The interview excerpts included illustrate how individual experiences directly relate to the uniquely liminal state imposed by the temporary visa regime, which keeps refugees in a space of ambiguity, marginalization, and transition. The excerpts are not intended to provide a comprehensive examination of the effects of the TPV on the mental health of asylum seekers. Rather, they illustrate the psychological repercussions of a temporal limbo, which has been created by global migration trends and national border politics. It is important to let these voices be heard as testimony to the impact of these trends. As McGuire and Georges point out, "Having been constituted by border politics as politically, legally, socially, racially and culturally unauthorised others, the subaltern voices of ... immigrants surface as 'moral others' who recount key dimensions of their migration experiences within multiple layers of context." 12

\section{Mental Health of Refugees}

Studies have found consistently high rates of mental illness among asylum seekers, including, in particular, depression, anxiety, and post-traumatic stress disorder syndromes. ${ }^{13}$ It has been noted that factors contributing to mental illness include not only the threat to life (and the reliving of such threats through current triggers), but the threat to what makes life meaningful. ${ }^{14}$ This meaning can be generated by a range of socially and individually experienced elements such as dignity; self-respect; honour; being able to provide physically and emotionally for children, family, and friends; natural justice; achieving potential; and having a sense of agency.

Migration and settlement impose unique stressors on migrants. Traumatic experiences before or during immigration, grief and loss, separation from family and friends, and isolation from others of a similar cultural background combine with cultural and linguistic difficulties, a low or decreased socio-economic status since immigration, and prejudice and discrimination, leading towards a greater tendency towards mental ill health. ${ }^{15}$ These mental health risks are more pronounced amongst the refugees and asylum seekers (onshore applicants) who seek protection and resettlement in Australia than in other migrants. ${ }^{16}$

It is generally accepted that the poor mental health status of asylum seekers is due to a combination of personal histories, including pre-migration exposure to trauma, and their current settlement and acculturation environment. The significance of the migration process itself has not been the subject of much research, with the notable exception being the impact of immigration detention on mental health. Evidence gleaned so far points to government policies of deterrence, such as prolonged detention and temporary protection visas, as prolonging and exacerbating mental illness. ${ }^{17}$ It is well established that the asylum-seeking process itself, and the material conditions of settlement and acculturation, can exacerbate the psychological trauma from which the individual is seeking refuge. The crucial issue remains, however, as to whether it is in itself a significant cause.

While all refugees have escaped from a traumatic past and share with other migrants the problems associated with settlement and acculturation, exclusionary government policies disproportionately disadvantage onshore asylum seekers. Because they are denied the stability to reconstruct their lives, they are unable to leave their trauma and uncertainty in the past, and their vulnerability to further stress is compounded. ${ }^{18}$ The analysis below suggests that in addition to existing and exacerbated conditions, mental illhealth amongst asylum seekers has been generated as a specific consequence of the temporary protection regime in Australia.

\section{Fleeing from Trauma}

The causal relationship between previous exposure to trauma and ongoing mental illness has been well documented. ${ }^{19}$ Martin notes that " $[\mathrm{t}]$ rauma on a mass scale leads to the shattering of identity on a personal level: the shattering of previously held assumptions; and the loss of trust, meaning, identity and a sense of future." ${ }^{20}$ Refugees and asylum seekers, by their very definition, are escaping persecution in their home countries. Most, if not all, will have experienced 
significant trauma prior to their flight, which may include torture, imprisonment, forced isolation, murder of family and friends, separation from family, rape, kidnapping, and war or civil conflict. ${ }^{21}$ Many will also have experienced severe disruptions to their daily existence, such as deprivation of food or water, lack of shelter, and being in a combat situation. $^{22}$

A study of forty asylum seekers in New South Wales found most to be suffering from physical or psychological ill health serious enough to warrant medical attention. ${ }^{23}$ Three-quarters of these people reported exposure to premigration trauma, and one in four had been tortured. More than one-third reported having been imprisoned and around one in three had family or friends murdered. ${ }^{24}$ Silove and Steel's analysis of five studies ${ }^{25}$ found nearly 80 per cent of asylum seekers reported exposure to serious trauma in their home countries. Many studies ${ }^{26}$ have concluded that those who arrive without valid documentation often have a more significant trauma history than authorized arrivals.

\section{Seeking Asylum: The Journey}

TPV holders are in a unique situation among refugees in Australia. Temporary visas are given to "unauthorized" arrivals - those people who arrive in Australia without valid visas - usually by way of a third country. ${ }^{27}$ The journey itself is often dangerous. Some asylum seekers have lived in refugee camps in a second country with little personal or material security, or given themselves into the hands of "people smugglers," often enduring a dangerous and unpredictable journey to Australia. Many have left home without travel documents, putting themselves in a precarious position along the way. This means that the process of arriving in Australia will be a source of further trauma for most TPV holders.

Susan's journey, for example, began when she followed her husband to Australia and led to her witnessing the drowning of several hundred people when the smuggler's boat she took from Indonesia capsized. Her experience is unique in its detail, but should not be dismissed as an extreme case. Journeys to host states can pose serious risks to the lives and health of asylum seekers, who would be unlikely to attempt such trips if substantive choices were available to them. Susan's narrative describes such a scenario:

We women were alone, without our husbands who had already fled, Since we were also in danger we decided to follow the paths of our husbands. We were living in "Al selmania" and Saddam was always threatening to bomb it. I use to get really scared every time I heard bombing, so I decided to travel with my children to Iran, scared about dying. I got to Iran and I intended to travel to Australia from there.

My trip started from Iran and it was easy because the Iranian government was happy for Iraqis to leave Iran. We only stayed in Iran for two months because the situation was getting very scary. Iraqis couldn't work and the situation was very hard. We left Iran for Malaysia by plane, and smugglers waited for us at the airport, and they told us that they'd take us to Indonesia very easily. We stayed for four days and then we crossed the Indian Ocean from Malaysia to Indonesia in a boat. We had a lot of problems in Indonesia, since we had gangs taking our luggage and some people who pretended they were from the police threatened to kill my son. They were all liars and they took all our money, it was a big conspiracy between the smugglers and the gang. After all this suffering, we got to Jakarta, Indonesia and we stayed for a week.

I didn't enter Australia safely. The smuggler was a liar and he gave us a very old boat, and told us that there will be about 170 people, however, there were 418 people from different nationalities. ... The men weren't allowed to inspect the boat that we would be sailing on. That boat was far away and the only way to get there was by smaller boats. First, women and kids were taken in this way to the main boat. All women were very busy taking care of their children, since some of them were not feeling well and were constantly throwing up (they were sea sick because the 'main' boat was very light). The number of passengers was very high, the children outnumbered the women and men, and there wasn't space for anyone to sit, or lie down and rest our legs. I was under the impression that we were heading to a larger boat. So I asked a man who wasn't feeling well if we were going to be transferred to a larger boat, he told me that this was the boat we would sail on. I was surprised because the boat was very small. We had no choice at this stage because we couldn't go back and we already paid the money. The smuggler left us a long time waiting [in Indonesia] before we got on the boat, so we already spent all our money. We had no choice but to accept the situation, we couldn't do anything if we went back. Everyone thought that getting to Australia is easy, even with a small boat $\cdots$

We went by sea from Indonesia towards Australia in October, and after 20 hours of sailing, the engine stopped and the boat flipped upside down, all other women and children died, only 45 survived from 418 people. Then we went back to Indonesia and we were put in a hotel by a human rights association, and they took care of us.

When everyone was sinking, I was all by myself, floating without 
anyone's help for a whole day. I saved myself and I didn't know anything about my son. The next day, Indonesian fishermen rescued us and they told me that my son was alive. ...It was very dark and cold, it was raining and I couldn't see anything around me. I was very thirsty and I was trying to drink from the rain, but the sea water which contained gasoline was going inside my mouth. So I was trying to breath from my nose, and struggling to stay alive. I expected death every second. ...

The smuggler knew that the boat will only last 1 or 2 days then stop, it's like he intended to kill us. When the boat stopped, the men told us that the engine cannot be fixed and that all we can do is pray, and scream for someone to find us and rescue us. In a second, the boat flipped upside down and the water came in, people started screaming, I opened my eyes and found myself under water. The boat over me and there were kids and women around me. They were swallowing the water, and dying, I could hear their screaming under water. I was telling myself, why is there all this unfairness in life? Why do human beings do these things to their brothers? I felt that all the ones who died felt that they were treated unfairly. I was thinking about my daughter, I wanted to see her, and I wanted to solve my son's problem. And my son who was with me, where is he now? I was wondering if he was alive, I just wanted to know, then die.

\section{Detention Experiences}

Unauthorized arrivals like Susan and her husband are put into immigration detention either in Australia or offshore while their claims are being processed. Most TPV holders will have been detained either in Australia or offshore as part of the government's Pacific Solution, whereby unauthorized asylum seekers are forcibly transferred to Pacific states that have agreed to host the status determination process. Mandatory detention of such asylum seekers is part of a global policy trend to deter and punish unauthorized arrivals. ${ }^{28}$ This policy continues despite statistics released by the Department of Immigration itself showing that over 85 per cent of recent detainees were accepted as genuine refugees higher than the corresponding figure for community-based (or authorized) applicants. ${ }^{29}$

The traumatizing effects of prolonged immigration detention have been well documented. A number of bodies including the UNHCR, the Human Rights and Equal Opportunity Commission (HREOC), the Australian Commonwealth Ombudsman, along with Amnesty Inter- national, Human Rights Watch, and medical practitioners have all expressed concern over the impact of this practice. ${ }^{30}$

One of the most disturbing studies on the effects of detention on the mental health of asylum seekers has been conducted by two psychologists, Sultan and O'Sullivan, one of whom was himself detained by the Australian authori- ties. ${ }^{31}$ Of the thirty-three detainees interviewed, all but one had symptoms of psychiatric distress: 85 per cent reported chronic depressive symptoms, 65 per cent had pronounced suicidal ideation, while seven exhibited signs of psychosis, including delusional beliefs and auditory hallucinations. Sultan and O'Sullivan characterized the psychological deterioration of detainees as having four stages, beginning with a "non-symptomatic stage" and degenerating through primary and secondary to tertiary depressive stages. The last of these manifests in severe psychiatric symptoms, including self-harm and self-mutilation, suicide attempts, and emotional disconnection from others. They report that nearly half the detainees in the study had reached the tertiary depressive stage.

As Sultan and O'Sullivan have documented, the longer people stay in detention, the more traumatized they become. When entering a detention centre, people like Peter quickly absorb the prevailing hopelessness and become demoralized. Their psychological state is then exacerbated by the indeterminate length of time to be spent in detention:

I was scared that I would never leave the camp because I found people who were in the camp for two years when I got there. Someone who comes looking for freedom stays in a camp for two years? Strange. He doesn't know what his destiny is. These cases made me doubt I would get the visa soon and I felt depressed and scared that my destiny would be like those who spent a long time in the camp, or those who were rejected. Did I come to Australia to live in a camp? I came here to feel like a human being. I had a nervous breakdown and was wondering how long I would have to live under the authority of these prisons.

Sultan and O'Sullivan's findings have been supported by numerous other studies. HREOC has documented many examples of suicide attempts and self-harming behaviour in detention centres. ${ }^{32}$ Another study of seventeen East Timorese asylum seekers at the Curtin detention centre exposed substantial levels of pre-migration trauma among detainees. All were suffering from PTSD, while sixteen were depressed and eleven suffered from anxiety. Steel and Silove $^{33}$ found that detained asylum seekers reported a much higher response to trauma categories (average of 12.4 out of a possible 16 major trauma categories) than asylum seekers in the community (average 4.8 out of a possible 16 for asylum seekers in the community), suggesting that the detention itself might be a contributing factor, either in itself or as a re-traumatizing influence. ${ }^{34}$ Some asylum seekers claim detention is more traumatic than the torture they have already endured. 
For many like Mary, the prison-like environment is a brutal reminder of all they have escaped and can trigger a traumatic stress response:

They used to always come to get our number (to count us). One day, they came in and I saw them, wearing the army gear, with the mobile phones, I felt like I was in Iraq and that the security was coming to take my son from me. At this moment, I had a nervous breakdown.

Similar findings are being reported in the United States. One study of seventy asylum seekers in detention ${ }^{35}$ found that although the median length of detention was shorter than that in Australia, 70 per cent stated that their mental health had worsened substantially in detention. Seventy-seven per cent reported significant levels of anxiety, 86 per cent were suffering from depression, half had PTSD, and one-quarter reported suicidal thoughts.

\section{Post-Detention Experience: Life on TPVs}

Asylum seekers assessed to be genuine refugees are provided with a temporary visa upon their release from detention. In addition to the trauma of forced migration, TPV holders face the added burden of a future which is unknown and out of their control. Not surprisingly, the post-migration environment for asylum seekers and for refugees with TPVs is characterized by high stress levels, often directly related to uncertainty, fear, and deprivation. Under these circumstances, people with significant experiences of past trauma are particularly vulnerable to re-traumatization and to an increase in the severity of anxiety and post-traumatic stress symptoms.

Post-migration stressors are triggered by the dislocation and distress which occur when a person is unable to achieve a satisfactory state of belonging and have been associated with increased symptoms of depression, anxiety, and PTSD. ${ }^{36}$ Indicators of successful settlement include the ability to speak the local language; obtain adequate employment; participate in the social, cultural, and economic life of the new country; achieve a sense of belonging and responsibility within the new culture; and enjoy meaningful relationships within the family, with friends, and within communities. ${ }^{37}$

The link between post-migration stressors and the absence of those factors critical for successful settlement is evident in TPV holders. For example, low English-language proficiency has been identified in many studies as a predictor of depression both in the short term ${ }^{38}$ and in the longer term. ${ }^{39}$ Depression is more likely to be diagnosed in those with low income or receiving welfare payments, ${ }^{40}$ or in those not able to find work. ${ }^{41}$ In one study, over half of the respondents experienced major stress related to fears of being sent home, or conversely, related to fears of being unable to return home in an emergency. ${ }^{42}$ Other stress-inducing factors identified included forced separation from one's family, unemployment, a lack of access to health and welfare services, and difficulties with the refugee visa application process. ${ }^{43}$ Discrimination and lack of social support or friends have been identified as major contributors to anxiety and depression in refugees. ${ }^{44}$ Interestingly, one study suggested that spending time with others from the same cultural background in some instances increased anxiety, as respondents reported that they had to "conform and respond to the expectations of their ethnic groups."45

Schweitzer, Buckley, and Rossi distinguish these "vulnerability factors" from "protective factors," that is, the skills and opportunities which enable asylum seekers to participate in the social, cultural, and economic life of their adopted country. Social support, language proficiency, and education are the key protective factors they identify. ${ }^{46}$ Unfortunately, if protective factors are not already in place they are very difficult to acquire. TPV holders have restricted access to services, either because they are ineligible or unable to pay for them. The pressure to find and keep a job often leaves little time for "luxuries" such as learning English, gaining qualifications, or accessing medical or counselling services. TPV holders' health is further undermined by their employment opportunities. Becoming economically self-sufficient is understandably the first priority for most, but the type of work commonly available is temporary, unskilled, and contractual, and does not provide sick leave provisions, prompting fears of losing their job if absent from work. ${ }^{47}$

The effect of past trauma on mental health is twofold. As already discussed, stresses of resettlement can exacerbate pre-existing mental disorders brought about by trauma, but the effects of past trauma may also inhibit successful settlement. The ability of asylum seekers to learn new skills, acquire education, and secure employment can be inhibited by psychological ill health caused by the traumas of their past. Without such skills asylum seekers are likely to remain marginalized, creating further depression, stress, and anxiety, and further disrupting their ability to participate and contribute.

In this way, the TPV policy deliberately and successfully creates an unsustainable life. Jim explains its effect on him:

I lived a good life in Iraq, so high life and technology doesn't mean much to me. My purpose is not the high life, but to feel safe, free, and to get a citizenship to feel that I belong somewhere. All I've seen so far doesn't mean much to me, given the type of visa that I was given. I feel that getting this visa put me back in the same situation of not knowing and not being settled. 
Concerns about the effects of the TPV on refugee health have been expressed by human rights groups and torture and trauma groups since the visa's inception. ${ }^{48}$ It remains "a particular irony of the Australian response to refugee crisis ... that the more traumatized are more likely to be detained and granted temporary protection rather than permanent protection." 49 The government's "deter and deny" policy punishes people for not entering Australia through channels which are authorized in advance. In the process it imposes the harshest restrictions on those people most in need of support.

Sengchanh argues that a fundamental question for our understanding of democracy is what we do about our noncitizens. ${ }^{50}$ In this respect, the deliberate social exclusion of the most disadvantaged members (or potential members) of a society reveals much about the society itself. In Australia the rhetoric of national identity has cultivated the negative qualities of the "stranger" as much as the virtues of the citizen and this binary has been used to justify exclusionary policies and practices. It is in this context that asylum seekers have been rhetorically constructed as illegitimate intruders. More specifically, the conditions attached to the TPV position asylum seekers outside the legal, moral, and political structures of society. Too often, the people so affected become invisible and their experiences are elided. Mary is one of these people:

I feel tied up. I don't know whether I'm living in Australia because I don't feel comfortable like the rest of Australian people. We're very tired mentally and we want to settle down. Our future and destiny is unknown. We don't have any freedom, like being in a prison. We've had enough suffering.

Like Mary, the TPV holders interviewed expressed overwhelmingly their frustration that they are unable to become a part of their new society in any meaningful way.

\section{Family Separation}

The policy of granting temporary protection is intended to deter others from attempting a similar journey. To do this effectively, the restrictions placed on the temporary visa are deliberately harsh. Many TPV holders interviewed felt that being separated from family is the hardest aspect of their existence. Susan's words sum up the feelings of many:

I want to talk to Mr John Howard and ask him to take everything away from me, but in return bring my son here, and put him in a camp. Even if I don't get to see him, at least I'll know that he's safe in the hands of the Australian government and close to me. I just want to protect my son in any way. I'm so depressed, my daughter is in Jordan and I haven't seen her in 7 years. My family is dispersed, my daughter has two children that I haven't seen, and my son is in Iran. My other son and I waited for so long in Indonesia when my husband was in Australia. We left our country and we had no choices. If it wasn't for the very hard life, we wouldn't have left our country.

Many writers have commented on the importance of the family unit, which "lessens the sense of isolation and loss and provides a justification and a direction for the future." 51 Family is a potent source of community and social infrastructure that provides meaning and a sense of identity. David questions the morality of punishing the few in order to deter the many, particularly when those being punished are children and other family members who have already suffered:

My wife was fired from her job because she was always pressured to make me go back to Syria. The government also pressured my family by stopping their financial income. They also kicked my children out of school after they fired my wife. My family was therefore with no income, my wife with no job and my children with no school. The situation was very bad and my children were suffering. Was it their fault? Even if I were guilty, they're children. Everyone I met here was willing to help, but because I had the TPV, the government didn't allow reunion. Was this protection visa given to me to protect me or to punish me?

Many asylum seekers could not afford to bring all their children with them to Australia, and those forced to leave family behind suffer guilt, anxiety, and depression. ${ }^{52} \mathrm{~A}$ secondary (and probably unforeseen) consequence of the policy is that people will attempt dangerous journeys to join their families, which in effect creates a demand for further "illegal" migration. In 1999, the Australian government was among those that passed a Conclusion on the Protection of the Refugee's Family at a meeting of the Executive Committee of the UNHCR. This recognized that family cohesion is important for society, and therefore deserves state protection. ${ }^{53}$ In this light, the family reunion restrictions of the TPV are particularly punitive, as people like David attest:

How much can we handle? The injustice of our own country, or the injustice of the Australian government? We came to Australia looking for mercy and peace, not to deal with the mental pressure that we're suffering from. I can't handle living away from my family, I don't have the capacity to deal with that.

\section{Economic Concerns}

Economic security is a key indicator of settlement success and many international studies on the economic integration of refugees have identified successful economic integration 
and well-being as being determined by the twin variables of refugees' social and human capital, and the social, political, and economic context of the host country. ${ }^{54}$ Education, citizenship, ethnicity, English-speaking ability, and length of residence were found to be the main predictors of integration success. The refugee populations in these studies generally compared unfavourably to the wider population and to other migrants, and correspondingly demonstrated downward occupational mobility and high levels of unemployment or underemployment.

A Melbourne study of TPV holders ${ }^{55}$ found that unemployment is high within this group, and that the little work available was often temporary, casual, and unskilled. With no access to English language classes, employment assistance programs, or vocational training, the opportunity to find work - much less, meaningful work - is severely limited. Accessing health care and counselling is constrained by financial and practical considerations, while the lack of sick leave provisions in this type of work prompts fears of losing employment and consequently prevents many from prioritizing their physical or mental health. Similarly, a recent report identified a range of barriers to employment faced by TPV holders stemming from the absence of settlement services following a period of detention including English language tuition, a lack of familiarity with the Australian labour market, and the loss of skills and confidence during the asylum seeking process. ${ }^{56}$ The temporary nature of their visa was an additional obstacle to employers who preferred employees with more secure status. Schweitzer, Buckley, and Rossi report that refugees with low income or on welfare were more likely to be diagnosed with depression. ${ }^{57}$ Peter found the restrictions imposed by the TPV denied him many rights and advantages afforded to citizens and other refugees:

We started looking at a way to get work, the first obstacle was the language. We weren't entitled to a free English course being a Temporary Protection Visa (TPV) holder, what sort of visa is this? We weren't entitled to learn the language, study, get married, or travel..., so what are we allowed to do? I want to improve myself and my qualifications, I want to study, but I'm not allowed. If I study, it means cutting off the social security income.

The conditions imposed by the TPV enforce a dependency that is neither the desire of the TPV holders nor in the interests of the Australian public. Hoffman argues that "(a)sylum seekers have been denied the opportunity to establish a moral relationship with the public, so their enforced marginality prevents the recognition of their so- cial legitimacy," 58 a condition he sees as much more insidious than medical or welfare dependency.

\section{Redetermination: Extending Uncertainty}

The policy of temporary protection denies TPV holders the psychological space to build "protective" factors and heal from the past. They are unable to envision a future for themselves in the prolonged uncertainty of their situation. Many who have lost hope for themselves see their children's future as the most important, and perhaps the only, consideration:

I don't have any wishes or any plans for the future. We came to Australia, and they gave us the TPV which destroyed all our hopes. We hoped to get the freedom, peace and to settle down. A person without hope is like a dead person. We feel that our life is destroyed because it's without hope. We don't plan anything for the future and have no hope but to get a permanent visa. We're old, but our children are going to school and learning English. - Sarah

The strain of living in a state of impermanence clearly takes its toll on TPV holders such as Jim and David, who are unable to move forward or end the limbo in which they find themselves:

I feel that I'm starting to live the same way I lived in Iraq or Iran. I haven't changed anything in my life, I moved from temporary circumstances, to another temporary... to third temporary circumstances. - Jim

I went to a lawyer and I told him that I don't want Australia. I went with Foundation House ${ }^{59}$ to Legal Aid ${ }^{60}$ and I told them that I didn't want to stay in Australia and that I wanted to go to another country. My children have no one and they're out of school, they told me that I'm already an asylum seeker here and can't apply again. I told them that I had a death sentence in my country and I was given another one in Australia. The problem was that we were told that we can apply for the permanent visa within three years. I went to a lawyer in the city and he told me that it's too early to apply, and to come after two years and apply for the permanent visa. — David

The refugee determination process itself is inherently traumatic. Researchers have noted that most asylum seekers arrive with a belief that their claim is meritorious and that they will quickly be granted asylum. ${ }^{61}$ They see Australia as a country that respects human rights and accepts refugees. The reality is that the determination process can take years, and holders of a temporary visa must reapply when their visa expires after three or five years. Under the 
current regime, this process of application and reapplication for protection may be endless.

Applicants must recount and relive the most distressing events of their lives in great detail to prove their claims are genuine. ${ }^{62}$ These statements are often disbelieved and discredited. ${ }^{63}$ The credibility of asylum seekers (or perceived lack thereof) has been shown to be one of the most common reasons for rejecting claims at the Refugee Review Tribunal, ${ }^{64}$ which is particularly concerning given the manifestations of PTSD and the likely impact this will have on the applicants' coherence, presentation, and memory. Pernice identified the possibility of refugees having developed a conditioned fear response regarding interviews, which makes them unlikely to present their case well. ${ }^{65}$

The requirement to go through the visa application process all over again will prolong the uncertainty and distress felt by temporary visa holders. The regulatory changes allowing TPV holders to apply for mainstream visas (outlined above) are specious, as they prolong the uncertainty and raise hopes with no guarantee of a permanent outcome. It is this aspect that prompted Marion Le to call it "one of the cruellest things this government has done." 66 Colin expressed a sense of helplessness around the lack of control over his future:

There is a hope that the circumstances will change. I feel comfortable in this country, I feel freedom, and I hope that my freedom is permanent. I have a great hope that the laws regarding us will change. I haven't applied for the permanent visa because from what I heard, whoever applied for it before the tenth month, will be considered. However, whoever applies after that has no hope. I'm thinking of the present and what's left of the three years. What comes next is something out of my control. If they wanted me to stay then I will, and if they want me to leave, then I will because I have no choice. The decision comes from the government.

The loss of hope is the most serious threat to psychological well-being and healing. Some TPV holders retain hope, but that hope is inextricably tied to being granted permanent status with all the rights it confers. Nobody in this study expressed hope of a positive future while they remained on a temporary visa.

\section{Prospects of Repatriation and Anticipatory Stress}

The very real threat of return to an asylum seeker's originating country creates a substantial source of stress. Sinnerbrink et al. found that over 80 per cent of asylum seekers expressed fear about being sent back to their countries of origin. ${ }^{67}$ Similarly, this study found that fear of repatriation was the most commonly stated anxiety among TPV holders as exemplified in this statement by Sarah:

We feel the same thing here and that's not being settled, uncomfortable, unsafe. My children's future and our future are unknown. We don't know when we'll be returned to our country, for Saddam to hang us. We can't plan our future. We are always worried if we couldn't stay in Australia, who would welcome us in their country? We always feel discriminated against. I don't want my children to be like me, no future, and no destiny and without and identity. I want to study and work, I want them to belong somewhere and have a citizenship. — Sarah

Alexander characterizes four policy manifestations in the transition from temporariness to permanence, fuelled by what he calls "the myth of return." 68 The stronger the hold this "myth" (that return will be possible and inevitable) has on policy makers, the more likely it is that they will adopt a "non-policy" towards immigrants. This is likely to be followed by the "guest worker" policy of tolerance without acceptance, which then moves towards either assimilationist or pluralist policies of inclusion. The TPV policy, which shares aspects of the "guest-worker" and "non-policy" typologies, can be seen as heavily premised on an assumption that refugees are willing, and most importantly able, to return. For Peter, this thought is unimaginable:

I started hoping that the criminal government will stay in Iraq, so that I'll get the permanent visa here, even though this is against common sense, and at the expense of my people and my family in Iraq who are suffering because of the government. Every Iraqi wishes that the government will collapse.

The interviewees were clear that the impermanent nature of their visa keeps them in a state of uncertainty and anxiety. They have lost everything that defined their previous lives and are yet unable to plan for their future and build new ones. Getting a permanent visa is the only solution that many - like Larry - can envisage:

We've suffered enough; I came to Australia to get a future for my children. We want peace and freedom. I still feel like I'm in prison. I can't travel anywhere, and I feel that this visa doesn't allow us to settle down. We don't know what's waiting for us, will we suffer again? In Iran, we were threatened by being returned to Iraq. I don't feel that my children have any future in Australia. All I want is a future for my children, I don't care about me, I'm old and I've suffered enough. We lie to our children and we tell them that we will get the permanent visa and that they have to study and not worry about anything. Yet, they still don't feel that they're settled because of the unknown 
future. For example, a teacher asked one of my children about his hopes and wishes for the future in Australia and what he wishes to happen in the future, He told her that he doesn't wish anything because he only lives temporarily in Australia. She then told him that he'll stay in Australia and no one will take him away. My son told her that his family is on a temporary visa and that after three years we'll be sent back to our country. The teacher wanted him to concentrate on his studies and not worry about these things, so she told him that they all (in this school) will stand by him and won't let anyone send him away. We live the fear of the temporary visa every day.

Steel found that TPV holders displayed twice the risk for PTSD as permanent residents, and expressed concern that the conditions imposed by the TPV are creating a new category of traumatic stress which he describes as chronic anticipatory stress. ${ }^{69}$ During his research into PTSD, he was struck by both asylum seekers and TPV holders reporting "that they were not troubled by intrusive memories of past traumatic incidents, but by terrifying images of imagined future traumatic events to themselves or their family."70 Steel considers this "future oriented PTSD" as a "core adaptive survival response" to a state of uncertainty, which will be virtually impossible to treat while the situation of impermanence remains. ${ }^{71}$ Mary, like many refugees, describes her material conditions associated with a TPV as being (re-)imprisoned:

The disadvantage was giving us the temporary visa. The advantage was the good treatment that we got from the Australian people who were nice to us, and loved us. We've suffered enough; I came to Australia to get a future for my children. We want peace and freedom. I still feel like I'm in prison. I can't travel anywhere, and I feel that this visa doesn't allow us to settle down. We don't know what's waiting for us, will we suffer again?

This heightened level of anticipatory stress, Steel suggests, may be responsible for torture and trauma services across Australia reporting a lack of responsiveness to standard treatment interventions. The standard interventions are premised on the subject having arrived at a place and time where they are able to feel safe, but for TPV holders,

the future threat they face is real and represents a likely outcome. In such circumstances, it could be argued that forms of exposure therapy, rather than having an habituating effect, are likely to have a sensitising effect to future trauma ... the use of temporary protection may inadvertently lock individuals into an irresolvable future oriented PTSD. ${ }^{72}$
For people like Helen, this fear is part of daily life:

How could I build hopes on nothing? I have no future, same with my children, my family. The future is unknown for me and my family, we live in fear and anxiety. I also worry that I'll get a mental illness that has no cure: madness.

\section{Conclusion}

Research undertaken concerning asylum seekers, detainees, temporary protection visa holders, and authorized refugees indicates that all these groups are at risk of ongoing mental illness. ${ }^{73}$ The evidence points to government policies of deterrence such as prolonged detention and temporary protection visas as perpetuating and exacerbating mental illness.

It is widely accepted that the "recovery environment" is important in helping trauma survivors overcome posttraumatic stress, anxiety, and depressive symptoms. Support can be difficult to elicit from personal networks in communities where a significant number of people have been affected by trauma and are unable to offer much support to others. ${ }^{74}$

Many asylum seekers find accessing health services a daunting task and lack trust in health professionals and the service provided. Pernice believes that many refugees find it difficult to accept that speaking with a mental health professional will not adversely impact upon his or her relatives' safety ${ }^{75}$ particularly since the past torture experiences of some will have been inflicted by doctors acting under instructions. ${ }^{76}$ These beliefs are sometimes reinforced in immigration detention when detainees are handcuffed during transportation to and from medical appointments, and where doctors have authorized (sometimes forcible) sedation for containment and removal of detainees. ${ }^{77}$

One of the greatest dilemmas for successful recovery is that the forms of therapy used with torture and trauma survivors are based on the assumption that trauma and torture are things of the past. ${ }^{78}$ Standard treatments are not effective if trauma continues to be experienced. Schweitzer, Buckley, and Rossi observe that "many of the psychological problems facing recently arrived refugees will only be resolved by material changes in their lives and current circumstances and by being reunited with their families."79 Under the current "protection" regime, this is unlikely to happen:

As an asylum seeker, I don't want a TPV, and I didn't come for that. I came here to settle down and I wanted to be in a country where they respect human rights. I wanted to give this country as much as it gives me. If after the three years, I'll be returned back, then it's better to return now. The possibility to extend 
the visa another three years doesn't help. The only thing that does is a permanent visa. - Colin

Many of the difficulties associated with settling in a new country are unavoidable. The TPV policy is not. For those who are escaping a traumatic past, the process of re-establishing their lives can be particularly fraught. As demonstrated in this article by the statements of TPV holders themselves, the temporary nature of their visas not only prevents them from beginning the process of recovery, but ensures that their journey through trauma is ongoing.

\section{Notes}

1. An earlier version of this paper is published by International Migration. The author and Refuge thank IM for allowing the reproduction of the article for this special issue of Refuge.

2. Z. Steel, "The Politics of Exclusion and Denial, The Mental Health Costs of Australia's Refugee Policy" (paper, $38^{\text {th }}$ Congress, Royal Australian and New Zealand College of Psychiatrists, Hobart, 12 May 2003).

3. F. Mansouri and M. Bagdas, "Politics of Social Exclusion: Refugees on Temporary Protection Visa in Victoria" (Geelong: Centre for Citizenship and Human Rights, Deakin University, 2002).

4. M. Leach and F. Mansouri, Lives in Limbo: Voices of Refugees under Temporary Protection (Sydney: University of New South Wales Press, 2004).

5. A. Bartlett, Answers to Questions Asked by Senator Andrew Bartlett and Taken on Notice, Supplementary Budget Estimates Hearing, 1 November 2005, online: <http://www.andrewbartlett.com/PDF-misc/answers-to-estimates-question s-nov05.pdf $>$ (accessed 12 May 2006).

6. Department of Immigration and Multicultural Affairs (DIMIA), "Overview of the changes," 27 August 2004, online: $<$ http://www.dimia.gov.au/refugee/tpv_thv/1.htm> (accessed 12 May 2006).

7. Bartlett.

8. Refugee Review Tribunal, RRT Cases Finalised by Country in 2005/06, 28 February 2006, online: <www.rrt.gov.au/stats/ finalised\%20by\%20country\%20this\%20year.pdf> (accessed 2 March 2006).

9. P. Mares, The Devil in the Detail, Institute for Social Research, Swinburne University of Technology, 26 August 2004, online: http://www.apo.org.au/webboard/print-version.chtml?filen ame_num $=00838$ (accessed 2 December 2004).

10. Bartlett.

11. R. Mann, "Sending Them Home: Refugees and the New Politics of Indifference," Quarterly Essay, Issue 13 (2004).

12. S. McGuire and J. Georges, "Undocumentedness and Liminality as Health Variables," Advances in Nursing Science 26, no. 3 (2003): 185-195.
13. Steel; R. Schweitzer, L. Buckley, and D. Rossi, "The Psychological Treatment of Refugees and Asylum Seekers: What Does the Literature Tell Us?" Mots Pluriels, no. 21 (May 2002).

14. Australasian Society for Traumatic Stress Studies, Submission to the National Inquiry into Children in Detention, Human Rights and Equal Opportunity Commission, 2003, online: http://www.hreoc.gov.au/human_rights/children_detention /submissions/astss .html (accessed 2 December 2004).

15. The National Action Plan for Promotion, Prevention and Early Intervention for Mental Health (Canberra: Commonwealth Department of Health and Aged Care, 2000).

16. S. Richardson et al., "Life in a New Land: The Experience of Migrants in Wave 1 of LSIA 1 and LSIA 2" (report to the Department of Immigration and Multicultural and Indigenous Affairs, National Institute of Labour Studies, Flinders University, Adelaide, 2002).

17. Steel; Z. Steel and D. Silove, "The Psychological Cost of Seeking and Granting Asylum," in International Handbook of Human Response to Trauma, ed. A. Y. Shalev, R. Yehuda, and A. C. McFarlane (New York: Academic/ Plenum Publishers, 2000).

18. Steel and Silove.

19. D. Silove and Z. Steel, The Mental Health and Well-being of On-shore Asylum Seekers in Australia (Sydney: Psychiatry Research and Teaching Unit, University of New South Wales, 1998); Steel and Silove, "The Psychological Cost of Seeking and Granting Asylum"; I. Sinnerbrink et al., "Compounding of Premigration Trauma and Postmigration Stress in Asylum Seekers, Journal of Psychology 131, no. 5 (1997): 463-471; D. Silove, Z. Steel, and C. Watters, "Policies of Deterrence and the Mental Health of Asylum Seekers, Journal of the American Medical Association 284, no. 5 (2 August 2000): 604.

20. H. Martin, "Temporary Protection Visas: Recovery from Trauma and Personal Identity," in Critical Perspectives on Refugee Policy in Australia, ed. M. P. Leach and F. Mansouri (Geelong: Centre for Citizenship and Human Rights, Deakin University, 2003), 185-190.

21. Silove and Steel; Schweitzer, Buckley, and Rossi..

22. Schweitzer, Buckley, and Rossi.

23. M. Harris and B. Telfer, "The Health Needs of Asylum Seekers Living in the Community, Medical Journal of Australia (MJA), 175 (2001): 589-592.

24. Silove, Steel, and Watters.

25. Silove and Steel.

26. A. Sultan and K. O'Sullivan, "Psychological Disturbances in Asylum Seekers Held in Long Term Detention: A ParticipantObserver Account," MJA 175 (2001): 593-596; From Persecution to Prison: The Health Consequences of Detention for Asylum Seekers (Boston and New York: Physicians for Human Rights and the Bellevue/NYU Program for Survivors of Torture, 2003), http://www.phrusa.org/campaigns/asylum_network/detention_execSummary /detention_pdf.pdf (accessed 14 June 2004).

27. The term "unauthorized" is controversial and arguably inaccurate. The Refugee Convention to which Australia is a signa- 
tory guarantees the right to seek asylum from persecution whether or not a person holds valid documentation upon arrival in the host state.

28. "By Invitation Only": Australian Asylum Policy. (New York: Human Rights Watch, 2002); Steel and Silove, "The Psychological Cost of Seeking and Granting Asylum."

29. Mann.

30. Steel; Health Conditions in Australia's Detention Centres, Amnesty International Australia, n.d., online: <http://www.amnesty.org.au/whats_happening/refugees/resources/fact_she ets/Detainees_Health?MySourceSession=dbf009320db2da3 50e7199d82d05b d5d > (accessed 2 December 2004); B. Loff, "Detention of Asylum Seekers in Australia, Lancet 359, no. 9308 (2 March 2002): 792; B. Loff et al., "'Inside’ Australia's Woomera Detention Centre," Lancet 359, no. 9307 (February 2002): 683; Silove and Steel.

31. Sultan and O'Sullivan.

32. Z. Steel and D. Silove, "The Mental Health Implications of Detaining Asylum Seekers," MJA 175 (2001): 596-599.

33. Steel and Silove, "The Mental Health Implications of Detaining Asylum Seekers."

34. Silove, Steel, and Watters.

35. From Persecution to Prison: The Health Consequences of Detention for Asylum Seekers.

36. Silove and Steel, 34.

37. S. Khoo and P. McDonald, "Settlement Indicators and Benchmarks: Report Submitted to the Department of Immigration and Multicultural Affairs" (Australian Centre for Population Research, Research School of Social Sciences, Australian National University, October 2001).

38. R. G. Blair, "Risk Factors Associated with PTSD and Major Depression among Cambodian Refugees in Utah," Health and Social Work 25, no. 1 (2000): 23-30; Richardson et al.

39. M. Beiser and F. Hou, "Language Acquisition, Unemployment and Depressive Disorder among Southeast Asian Refugees: A 10 year Study," Social Science and Medicine 53 (2001): 13211334.

40. Schweitzer, Buckley, and Rossi.

41. Harris and Telfer; Silove and Steel.

42. Silove and Steel, 34.

43. Schweitzer, Buckley, and Rossi.

44. R. Pernice and J. Brook, 'Refugees' and Immigrants' Mental Health: Association of Demographic and Post-Immigration Factors," Journal of Social Psychology 136, no. 4 (1996): 511; Harris and Telfer.

45. Pernice and Brook.

46. Schweitzer, Buckley, and Rossi.

47. G. Marston, Temporary Protection Permanent Uncertainty (Melbourne: Centre for Applied Social Research, Royal Melbourne Institute of Technology, 2003.)

48. Steel.

49. Ibid., 17.

50. Ibid.

51. Marston, 24-25.
52. S. Manning, "Surviving Not Thriving: Refugee Children Granted Temporary Protection Visas" (report prepared for Senator Lyn Allison, Australian Democrats, May 2003); S. Chakma, "Refugee Family Reunification" (background paper prepared for "Hopes Fulfilled or Dreams Shattered? From Resettlement to Settlement" Conference, Sydney, 23-28 November, 2005.

53. V. Sengchanh, "Refugees: Two Lifetimes in One," E Law: Murdoch University Electronic Journal of Law 8, no. 4 (December 2001), 13.

54. M. Potocky and T. P. McDonald, "Predictors of Economic Status of Southeast Asian Refugees: Implications for Service Improvement," Social Work Research 19, no. 4 (1995): 219; N. K. Lamba, "The Employment Experiences of Canadian Refugees: Measuring the Impact of Human and Social Capital on Quality of Employment," Canadian Review of Sociology and Anthropology (CRSA) / Revue Canadienne de Sociologie et Anthropologie (RCSA) 40 (2003): 1.

55. Marston.

56. Dumped at the Gate: From Detention to Despair. Recommendations for Minimum Standards for the Post-Detention Settlement of Asylum Seekers (Melbourne: Asylum Seeker Resource Centre, December 2005).

57. Schweitzer, Buckley, and Rossi.

58. N. Hoffman, Labour Rights and Border Protection: Attempts at a Viable Life on the Temporary Protection Visa (Industrial Relations Research Centre, University of New South Wales, 2003).

59. Foundation House is a service provider for survivors of torture and trauma.

60. Legal Aid is provider of free legal assistance.

61. Sultan and O'Sullivan; From Persecution to Prison: The Health Consequences of Detention for Asylum Seekers.

62. Steel and Silove, "The Mental Health Implications of Detaining Asylum Seekers.

63. Manning; Sultan and O'Sullivan.

64. R. Manne, TPV Holders in Queensland (Brisbane: Brisbane City Council, 2001); S. Cauchi, M. Ierodiaconou, and A. Perry, "The Invisible Women: A Report on Gender-Based Persecution Claims by Women Asylum Seekers in Australia” (Melbourne: Feminist Lawyers and Women's Rights Action Network Australia, 2003).

65. R. Pernice, "Methodological Issues in Research with Refugees and Immigrants," Professional Psychology: Research and Practice 25, no. 3 (1994): 207-213.

66. A. Zable, "Prolonging the Agony," The Age, 28 July 2004, online: <http://www.theage.com.au/articles/2004/07/27/ 1090693960478.html> (accessed 28 July 2004).

67. Sinnerbrink et al.

68. Alexander.

69. Steel.

70. Ibid.

71. Ibid., 18.

72. Ibid.

(C) Fethi Mansouri and Stephanie Cauchi, 2006. This open-access work is licensed under a Creative Commons Attribution-NonCommercial 4.0 International License, which permits use, reproduction and distribution in any medium for non-commercial purposes, provided the original author(s) are credited and the original publication in Refuge: Canada's Journal on Refugees is cited. 
73. Ibid.; From Persecution to Prison: The Health Consequences of Detention for Asylum Seekers; Dumped at the Gate: From Detention to Despair; Steel and Silcove.

74. Schweitzer, Buckley, and Rossi.

75. Pernice.

76. Sultan and O'Sullivan.

77. Ibid.

78. Steel.

79. Schweitzer, Buckley, and Rossi.

Fethi Mansouri is deputy director for the Centre for Citizenship and Human Rights and Associate Professor in Middle Eastern Studies at Deakin University. He has conducted research and published in the areas of Middle Eastern studies, multicultural education, and comparative refugee settlement. His book (with Michael Leach), Lives in Limbo: Voices of Refugees under Temporary Protection, is published by University of New South Wales Press (2004).

Stephanie Cauchi is a research fellow at the Centre for Citizenship and Human Rights at Deakin University. She has conducted research on the legal aspects of the determination process and is currently inivolved in a study on the longitudinal effects of the temporary protection regime.

(C) Fethi Mansouri and Stephanie Cauchi, 2006. This open-access work is licensed under a Creative Commons Attribution-NonCommercial 4.0 International License, which permits use, reproduction and distribution in any medium for non-commercial purposes, provided the original author(s) are credited and the original publication in Refuge: Canada's Journal on Refugees is cited. 